\title{
Serum C - reactive protein and Pro-Calcitonin as an Indicator in Post-Operative Infection after Hepatobiliary Surgery
}

\author{
CC Joshua ${ }^{\circledR 1}$, V Sreejith ${ }^{\odot 2}$, A. Sreekumar ${ }^{\oplus 3}$ \\ ${ }^{1}$ Associate Professor, Department of General Surgery, PK Das Institute of Medical Sciences, Vaniyamkulam, Ottappalam, Kerala, India, ${ }^{2}$ Senior resident, Sciences \\ Ottapalam, Department of General Surgery, PK Das Institute of Medical Sciences, Vaniyamkulam, Ottappalam, Kerala, India, ${ }^{3}$ Professor, Department of General \\ Surgery, PK Das Institute of Medical Sciences, Vaniyamkulam, Ottappalam, Kerala, India.
}

\section{Abstract}

Background: Major hepato-biliary surgeries carry a high risk for post-operative sepsis. Recent therapeutic advances both medical and surgical have improved early post-operative outcome. Considering the difficulties in diagnosis of infection in critically ill patients an early sensitive and specific marker for sepsis would be of interest. Studies have shown that C - reactive protein (CRP) and pro calcitonin (PCT) are acute phase reactants and good independent early markers of post-operative sepsis, severe or septic shock. This aspect has not been evaluated in the hepatobiliary surgeries. More over there is no data available from the Indian sub-continent in this aspect. This study aims to evaluate the efficacy of serum CRP and PCT levels after hepatobiliary surgery for diagnosis of postoperative complication. Subjects and Methods: This is a cross-sectional diagnostic study has conducted in 42 patients who all are satisfying the inclusion criteria. Study duration was From August 2017 to July 2019, conducted on patients between 18-80yrs of age undergoing hepato-biliary surgery, in surgical wards of PK Das Institute of Medical Sciences. Study variables include age, sex, pre-operative serum albumin level, pre and post-operative S.CRP AND S.PCT levels. On post-operative day 4 and day 7 S.CRP and S.PCT are monitored and its predictability also measured. . Descriptive statistical analysis will be carried out using SPSS (IBM). The p-value of less than 0.05 will be taken as significant. Results: out of 42 patients studied, 30 patients developed post-operative complications. Pre-operative serum C - reactive protein and serum procalcitonin measured compared with pre-operative serum albumin was significant identifying post-operative complications (P-value 0.02). On post-operative day 4 and 7 value was significant in post-operative patients with P-value of 0.04 vs. 0.046 respectively. Similarly serum procalcitonin values also were significant on postoperative day (POD) 4 and 7 with P-value of 0.02 and 0.03 . Sensitivity and specificity of S.PCT was more compared to S.CRP (92 vs $90 \%$ in sensitivity and $100 \%$ vs $80 \%$ in specificity respectively. This study shows those who were clinically septic post operatively have statistically elevated levels of serum CRP and Procalcitonin. Conclusion: S.PCT is more sensitive and specific as a marker of post operative infection following hepato biliary surgery. Early identification of patients with insidious septic illness allows early therapeutic intervention which may favorably influence outcome.

Keywords: Serum CRP, Serum PCT, post operative Infection, Hepato-biliary surgery

Corresponding Author: V Sreejith, Senior resident, Sciences Ottapalam, Department of General Surgery, PK Das Institute of Medical Sciences, Vaniyamkulam, Ottappalam, Kerala, India.

E-mail: sreejithv146@gmail.com

Received: 11 January 2020

Revised: 01 February 2020

Accepted: 08 February 2020

Published: 26 May 2020

\section{Introduction}

Hepato-biliary surgeries carry a high risk for post-operative sepsis. ${ }^{[1]}$ Recent therapeutic advances both medical and surgical have improved early post-operative outcome. Despite this progress certain patients remains at high risk of infection and with increased incidence of morbidity and mortality. During the post-operative period sepsis can be difficult to distinguish from other non-infectious situations such as postoperative systemic inflammatory response syndrome (SIRS), related to surgical trauma. ${ }^{2]}$ SIRS can be self-limiting or may progress to severe sepsis or septic shock. ${ }^{[3]}$ Early diagnosis and treatment of septic patients may greatly improve outcome. Considering the difficulties in diagnosis of infection in critically ill patients an early sensitive and specific marker for sepsis would be of interest. Recent studies have shown that $\mathrm{C}$ - reactive protein (CRP) and pro calcitonin (PCT) is good independent early inflammatory marker of postoperative sepsis, severe or septic shock after major hepatobiliary surgery. ${ }^{[4]}$ 
CRP acts as an opsonin for bacteria, parasites, and immune complexes activating the classical complement pathway. ${ }^{[5]}$ The plasma levels of CRP in most healthy subject are usually $1 \mathrm{mg} / \mathrm{dl}$ with normal being termed as $<10 \mathrm{mg} / \mathrm{dl}$. Plasma levels begin increasing within 4-6 hrs. After initial injury and continue to increase several hundred folds within 24-48 hrs. CRP remains elevated during the acute phase response, returns to normal with restoration of tissue structure and function. CRP is sensitive systemic marker of inflammation and tissue damage but is not specific for infection. Surgical trauma induces a significant increase in CRP levels, which can reduce its predictive value for the diagnosis of infection in the early post-operative period.

Procalcitonin (PCT), the prohormone of calcitonin was first described as a biochemical marker of infection in 1993. ${ }^{[6]}$ It is identified as a diagnostic marker for infectious or septic processes and correlates better with severity as CRP814 , PCT is an acute phase protein and is the precursor of calcitonin. In healthy individual, PCT serum concentrations are very low $(<0.5 \mathrm{mg} / \mathrm{dl})$. The half-life of PCT is about 26 to $30 \mathrm{hrs15-17.} \mathrm{Neuroendocrine} \mathrm{cells} \mathrm{of} \mathrm{solid} \mathrm{organs} \mathrm{(lung,}$ kidney, pancreas, adrenal gland, and liver) might be the source of PCT during an inflammatory procedure. Extra thyroid cell, such as macrophages, monocytes and liver cells may play a role in the PCT production during sepsis. ${ }^{[7,8]}$ The main hypothesis as far as the PCT induction is concerned, presents that the stimulation for PCT elevation is a result of a systemic challenge of the organism with bacterial end toxin and bacterial poly-saccharides 2B. Bacterial end toxins are potent stimuli for PCT synthesis, which exhibits faster kinetics than CRP, PCT is released in to the circulation 3-4 hours after an injection of end toxins, reaching peak levels after 8-24 hrs, while CRP peaks at $36-50 \mathrm{hrs}$ after stimulus. ${ }^{[9,10]}$

The serum concentration of PCT is increased in patients with severe bacterial, fungal, or parasitic infections, whereas in those with viral infections, inflammatory responses of noninfectious origin, auto immune diseases or allergic reactions there is no, or only a minor, effect on the pro calcitonin concentration. So there is a definite role of CRP and PCT as an indicator of postoperative infection in major surgeries. This aspect has not been evaluated in the hepatobiliary surgeries. More over there is no data available from the Indian subcontinent in this aspect. So, the study has conducted to evaluate the efficacy of serum levels of C-reactive protein and serum procalcitonin as a marker for early diagnosis of post-operative infection after hepato-biliary surgery.

\section{Aim}

To evaluate the efficacy of serum CRP and PCT levels after hepatobiliary surgery for diagnosis of postoperative complication.

\section{Subjects and Methods}

This study was a Cross-sectional diagnostic study, conducted in the department of surgery, PK Das institute of Medical Sciences Ottappalam, Kerala, India for a period of 2 years from August 2017 to July 2019 in 42 patients who are undergoing Hepato-biliary surgery. Patients undergoing surgery for hepato-biliary diseases between $18-80$ years of age, both sexes, patient willing to give valid informed consent and patients with post-operative stay at least for 7 days were included in the study. Those who are with age $<18 \mathrm{yrs}$ and $>80 \mathrm{yrs}$, pregnancy, emergency surgery, ongoing systemic infection prior to surgery, immuno compromised patients, patients with malignancies not involving hepato-biliary system and patients not giving valid informed consent were excluded from this study. The Outcome variables of this study were 1)Sensitivity and specificity of CRP in detecting post-operative infections after hepato-biliary surgery, 2)Sensitivity and specificity of PCT in detecting post-operative infections after hepato-biliary surgery, and 3)Comparing efficacy of S.CRP and S.PCT in different post-operative periods

\section{Study procedure and working definition}

1. Pre-operative serum CRP and procalcitonin levels will be measured as baseline levels.

2. Post-operative course of the patient will monitor on day to day basis. The post-operative site of infectious complications will be measured and classified.

3. Serum procalcitonin and CRP levels will be measured on POD 4 and 7.

4. Post-operative infections were defined as

- Persistent fever (>3days with leukocytosis)

- All types of Surgical site infections: Purulent discharge, symptoms of erythema, pain, local edema or diagnosis of surgical site infections by surgeon

- Intra-abdominal fluid collection/drain volume : $>30 \mathrm{ml} /$ day for consecutive 3 days (except in T-tube drain)

- Blood culture: any growth except $\mathrm{S}$ epidermidis after 48 hrs of incubation in 2 blood cultures

- Urine culture :105 organisms $/ \mathrm{ml}$ in the presence of pyuria

- Pulmonary complications: fever, leukocytosis, purulent sputum with or without chest $\mathrm{X}$-ray changes

\section{Statistical analysis}

Data were summarized as numbers and percentages of patients, with medians and ranges were indicated. The statistical methods included chi square test and student $\mathrm{T}$ test were appropriate. Significance was assumed if the probability of first degree error were $p<0.05$. The data were analyzed using SPSS version 22.0. 


\section{Results}

Table 1: Demographic characteristics.

\begin{tabular}{llll} 
& Range/number & Mean & $\begin{array}{l}\text { Percentage } \\
(\%)\end{array}$ \\
$\begin{array}{l}\text { No. of } \\
\text { patients }\end{array}$ & 42 & - & - \\
Age (years) & $20-66$ & 42 & - \\
Male & 11 & - & 26.2 \\
Female & 31 & - & 73.8 \\
\hline
\end{tabular}

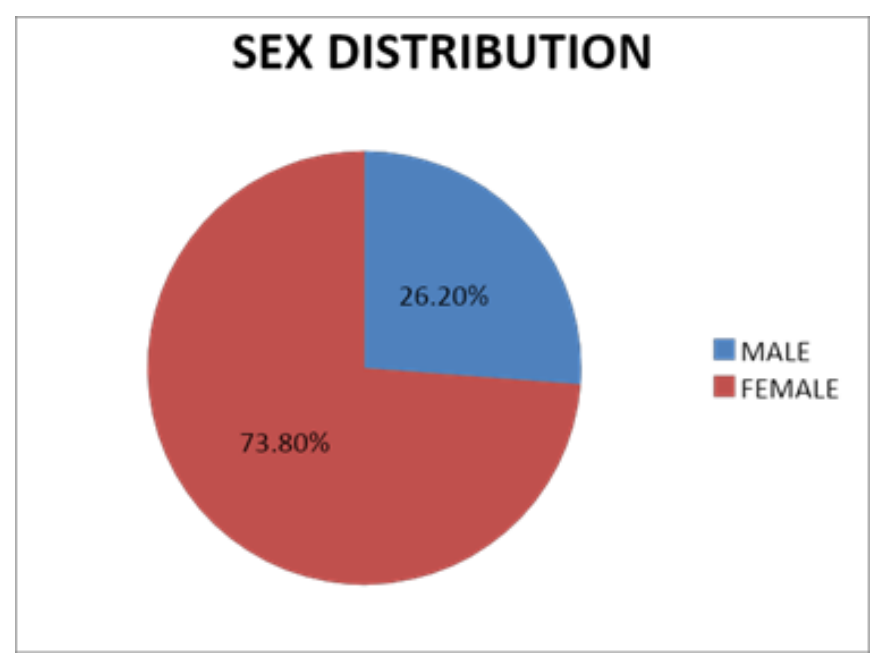

\section{Figure 1: Distribution of males and females}

\section{Demographic Characteristics}

Forty two patients admitted in the surgical wards of PKDIMS hospital during the study period between September 2017 and July 2019, who all are fulfilling inclusion criteria were included in the study. The average age of the population was $42 y$ rs, ranging from 20 to 66yrs. In the present study, females dominated Males with a ratio of 2.8:1(11:31) respectively. [Table 1, Figure 1]

\section{Distribution of co-morbidities among infected patients}

In this study Post-operative infection was increased in female than in male with a percentage of $70 \%$ vs $30 \%$ respectively. Out of 30 infected patients 4 were diabetic (13.3\%) and 7 were hypertensive(30.4\%). The incidences of co- morbidities like Diabetes, hypertension, smoking, alcohol and tobacco chewing are shown in [Table 2].

\section{Clinical presentation of patients}

The most common clinical presentation was dyspepsia in 41 patients $(97.6 \%)$, followed by abdominal pain in 19 patients $(45.2 \%)$ clinical features are described in [Figure 2].

\begin{tabular}{|c|c|c|}
\hline Co-morbidities & Yes & $\begin{array}{l}\text { Percentage of pos- } \\
\text { itive patients }(\%)\end{array}$ \\
\hline Diabetes & 4 & 13.3 \\
\hline Hypertension & 7 & 30.4 \\
\hline Smoking & 7 & 30.4 \\
\hline Alcoholism & 11 & 36.7 \\
\hline $\begin{array}{l}\text { Chewing tobacco } \\
\text { products }\end{array}$ & 23 & 76.7 \\
\hline
\end{tabular}

\section{Pathological diagnosis}

Cholelithiasis with cholecystitis was the most common histological diagnosis in the study population, seen in $21(50 \%)$ followed by cholelithiasis with choledocholithiasis in $13(30.9 \%)$ patients. Various pathological diagnoses have been given below in the table and figure. [Table 3]

\begin{tabular}{lll}
\hline \multicolumn{2}{l}{ Table 3: Pathological diagnosis } & \\
\hline $\begin{array}{l}\text { Diagnosis } \\
\begin{array}{l}\text { Cholelithiasis } \\
\text { with cholecystitis }\end{array}\end{array}$ & 21 & 50 \\
$\begin{array}{l}\text { Cholelithiasis } \\
\text { with choledo- }\end{array}$ & 13 & 30.9 \\
cholithiais & & \\
$\begin{array}{l}\text { Benign biliary } \\
\text { stricture }\end{array}$ & 2 & 4.7 \\
$\begin{array}{l}\text { Type 1c chole- } \\
\text { dochal cyst }\end{array}$ & 2 & 4.7 \\
$\begin{array}{l}\text { Type 1b chole- } \\
\text { dochal cyst }\end{array}$ & 1 & 2.3 \\
$\begin{array}{l}\text { Periampullary } \\
\text { carcinoma }\end{array}$ & 2 & 4.7 \\
$\begin{array}{l}\text { Type 2 mirizzi’s } \\
\text { syndrome }\end{array}$ & 1 & 2.4 \\
\hline
\end{tabular}

\section{Surgical procedures performed}

\section{Post-operative complications}

In our study, out of 42 patients 30 patients developed post operative complications. One third of the infectious complications were localized in the abdomen. [Table 6, Figure 3]

Serum CRP levels in post-operative period of infected patients

Among 30 patients who were infected in early post-operative period, ie POD 4 S.CRP value ranged from $68-171 \mathrm{mg} / \mathrm{dl}$ with mean of $120 \mathrm{mg} / \mathrm{dl}$ and standard deviation of $+/-2.61$. These findings were statistically significant with $\mathrm{P}$ value of 0.04 , 


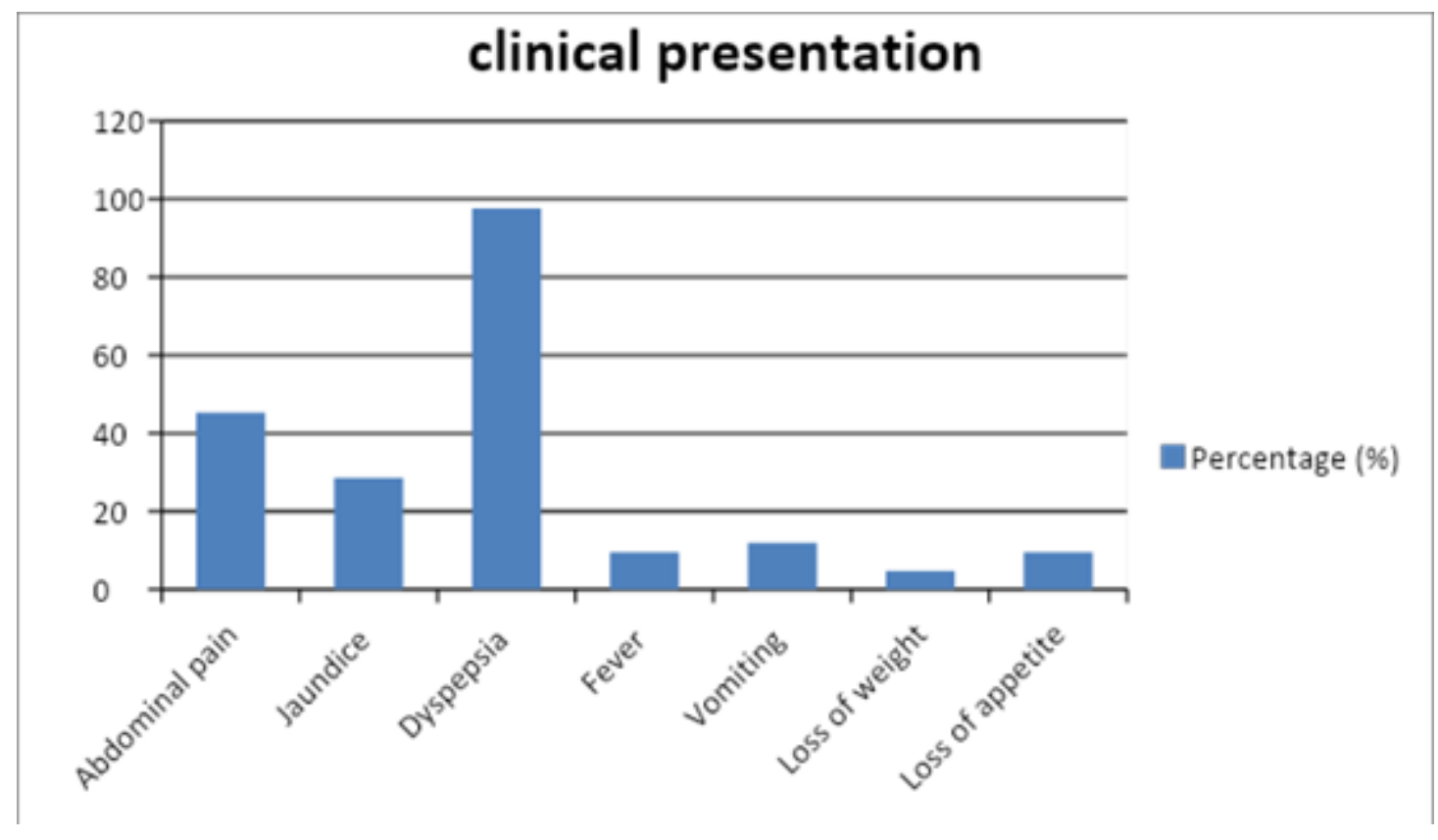

Figure 2: Showing distribution of various clinical presentations.

whereas post-operative day 7 S.CRP value ranged from 1.3 to $55 \mathrm{mg} / \mathrm{dl}$ in infected patients and it was also statistically significant with P-value of 0.043 .

Pre operative CRP value of infected patients ranged from $0.1 \mathrm{mg} / \mathrm{dl}$ to $4.1 \mathrm{mg} / \mathrm{dl}$. However this relation was not statistically significant with P-value of 0.49 . [Table 8 ]

\section{PCT levels on post-operative day 4 and day 7 in infected patients}

The value of serum levels of procalcitonin in 30 infected patients varies differently on early post-operative periods. On day 4 of post-operative period, value ranges from 0.5 to $2.2 \mathrm{ng} / \mathrm{dl}$ and mean value of $1.5 \mathrm{ng} / \mathrm{dl}$ with standard deviation of $+/-1.1$. These results were statistically significant with a $P$ value of 0.02 . The post-operative day 7 value of S.PCT ranged from $0.2 \mathrm{ng} / \mathrm{dl}$ to $1.5 \mathrm{ng} / \mathrm{dl}$. The mean value was $1.3 \mathrm{ng} / \mathrm{dl}$ with standard deviation of $+/-1.2$. This finding also was statistically significant with $p$ value of 0.03 . [Table 9]

\section{Predictability}

\section{Discussion}

Early identification of infections is still a challenge for clinicians. The general consensus is not to provide antibiotics for every suspected infection because emerging issues with bacterial resistance. Therefore marker for bacterial infection will be most helpful. Based on this analysis, we observed that PCT levels were more accurate markers for bacterial infection than were CRP levels, whereas CRP also has significance in predicting infection on postoperative day 4 .

Our findings are based on a prospective evaluation of 42 consecutive patients who were satisfying the inclusion criteria. In line with others, the number of clinical events ( 30 patients with intra-abdominal infections) was good for this group of study, which doesn't limits the statistical power of our analyses. Our study provides support for the view that serial measurements of CRP and PCT on day 4 and 7 after hepatobiliary pancreatic resection are useful for identifying patients at risk for developing intra-abdominal Infections. We suggest that, in patients with persisting high, or even increasing, CRP and PCT values after POD 4, diagnostic efforts should be considered to exclude any intra-abdominal collection.

In our study, an infectious complication was encountered after hepatobiliary surgery resection in one out of every three patients, and two third of the infectious complications were localized surgical site infections are most common cause of infection. Intra-abdominal abscess, which are still a potentially life-threatening condition unfortunately, the diagnosis is often made on POD 7 or later, when many patients present with signs of serious illness or even sepsis, which was also true in the present study. Thus, a method for the early identification of patients at risk for intra-abdominal infection would be of clinical importance. Results of Present study are much similar to the study conducted by P.Mathisessen et al, ${ }^{[11]}$ on the role of S.CRP in detecting anastomotic leaks and intra- 
Table 4: Showing the various surgical procedures undergone by the patients

\begin{tabular}{lll}
\hline Procedure & No. of patients & Percentage (\%) \\
$\begin{array}{l}\text { Laparoscopic } \\
\text { cholecystectomy }\end{array}$ & 9.5 \\
$\begin{array}{l}\text { Open cholecys- } \\
\text { tectomy }\end{array}$ & 40.5 \\
$\begin{array}{l}\text { Open cholecys- } \\
\text { tectomy with }\end{array}$ & 9.5 \\
CBD exploration \\
and primary \\
closure of CBD
\end{tabular}

abdominal collection.

Postoperatively, PCT levels in septic patients were increased, however, on day 4 had PCT levels significantly higher than the preoperative PCT. As septic events always occurred after day 2 in our study, PCT was an early marker of postoperative infections following major hepatobiliary surgery. The cutoff of PCT levels to diagnose postoperative sepsis on day $4(1.5 \mathrm{ng} / \mathrm{dl})$ showed good sensitivity $(80 \%)$ and specificity $(100 \%)$. Whereas the study done by Mokart et al, ${ }^{[5]}$ showed the cut off value of S.PCT levels to diagnose post-operative infection $(1.1 \mathrm{ng} / \mathrm{dl})$ showed good sensitivity $(81 \%)$ and specificity (72\%), more similar to our present study

A study by Simon et al, ${ }^{[12]}$ where they did a meta-analysis study to evaluate the accuracy of determination of PCT and

\begin{tabular}{lll}
\hline \multicolumn{3}{l}{ Table 5: Post-operative complications } \\
\hline Variables & No. of patients & Percentage (\%) \\
\hline $\begin{array}{l}\text { Surgical site } \\
\text { infections }\end{array}$ & 22 & 52.4 \\
$\begin{array}{l}\text { Intra-abdominal } \\
\text { collection/ } \\
\text { abscess }\end{array}$ & 4.7 \\
$\begin{array}{l}\text { Blood infec- } \\
\text { tions(fever with } \\
\text { leukocytosis \& } \\
\text { culture positive) }\end{array}$ & 11.9 \\
$\begin{array}{l}\text { Urinary tract } \\
\text { infection }\end{array}$ & \\
$\begin{array}{l}\text { Central line } \\
\text { infection }\end{array}$ & \\
\hline
\end{tabular}

Table 6: S.CRP levels on post-operative day 4 and day 7 of infected patients.

\begin{tabular}{|llll}
\hline Variables & $\begin{array}{l}\text { Range } \\
(\mathbf{m g} / \mathbf{d l})\end{array}$ & $\begin{array}{l}\text { Mean } \\
\text { SD }\end{array}$ & P-value \\
\hline Pre op & $0.1-3.9$ & $1.44+/-$ & 0.49 \\
S.CRP & & 0.84 & \\
POD 4 CRP & $68-171$ & $120+/-2.61$ & 0.04 \\
\hline POD 7 CRP & $1.3-55$ & $\begin{array}{l}30.18+/- \\
4.1\end{array}$ & 0.043 \\
\hline
\end{tabular}

Table 7: S.PCT levels on post-operative day 4 and day 7 of infected patients.

\begin{tabular}{llll}
\hline Variables & $\begin{array}{l}\text { Range } \\
(\mathbf{n g} / \mathbf{d l})\end{array}$ & $\begin{array}{l}\text { Mean } \\
\text { SD }\end{array}$ & P-value \\
$\begin{array}{l}\text { Pre OP } \\
\text { S.PCT }\end{array}$ & $0.02-1.8$ & $\begin{array}{l}0.62+/- \\
0.43\end{array}$ & 0.46 \\
Post op day & $0.5-2.2$ & $1.5+/-1.1$ & 0.02 \\
4 S.PCT & & & \\
Post op day & $0.2-1.5$ & $1.3+/-1.2$ & 0.03 \\
7 S.PCT & & & \\
\hline
\end{tabular}

Table 8: Infective predictability of CRP

\begin{tabular}{|c|c|c|c|c|}
\hline Variables & S.CRP & & Sensitivity & Specificity \\
\hline POD 4 & $\begin{array}{l}>/= \\
\mathrm{mg} / \mathrm{dl}\end{array}$ & 110 & $90 \%$ & $92 \%$ \\
\hline POD 4 & $\begin{array}{l}>/= \\
\mathrm{mg} / \mathrm{dl}\end{array}$ & 80 & $60 \%$ & $92 \%$ \\
\hline POD 7 & $\begin{array}{l}>/= \\
\mathrm{mg} / \mathrm{dl}\end{array}$ & 20 & $70 \%$ & $92 \%$ \\
\hline POD 7 & $\begin{array}{l}>/= \\
\mathrm{mg} / \mathrm{dl}\end{array}$ & 10 & $87 \%$ & $70 \%$ \\
\hline
\end{tabular}


Table 9: Infective predictability of PCT

\begin{tabular}{llll}
\hline Variables & S.PCT & Sensitivity & Specificity \\
POD 4 & $>/=1.5 \mathrm{ng} / \mathrm{dl}$ & $70 \%$ & $100 \%$ \\
POD 4 & $>/=1 \mathrm{ng} / \mathrm{dl}$ & $90 \%$ & $92 \%$ \\
POD 7 & $>=1.5 \mathrm{ng} / \mathrm{dl}$ & $90 \%$ & $92 \%$ \\
POD 7 & $>/=1 \mathrm{ng} / \mathrm{dl}$ & $70 \%$ & $100 \%$ \\
\hline
\end{tabular}

CRP levels for the diagnosis of infection. The PCT levels was more sensitive and specific than CRP level for differentiating bacterial from non-infective cause of inflammation which were comparable to our study in sensitivity but in sensitivity our study shows almost $100 \%$ specificity during post-operative day 4. In our study the sensitivity and specificity of S.CRP on POD 4 was $60 \%$ and $92 \%$ when cut off value set above $80 \mathrm{mg} / \mathrm{dl}$, whereas S.PCT sensitivity and specificity was above $90 \%$ which shows superiority of S.PCT monitoring.

In the study by Oberhofer et al, ${ }^{[13]}$ S.CRP and S.PCT concentration are increased in the early post-operative period with a significant difference between patients with and without complications. Here they mentioned about the high predictability of infection by S.CRP and S.PCT on day 2 of post-operative period when cut off value set as $99 \mathrm{mg} / \mathrm{dl}$ and $1.34 \mathrm{ng} / \mathrm{dl}$ respectively. It is almost comparable to our present study according to POD 4 value of sensitivity and specificity.

Mallet et al, ${ }^{[14]}$ conducted a study on 133 (48 women and 85 men) who underwent surgery, the overall rate of septic complication was $39.1 \%$ (52 patients out of 133 patients). Leaks were more frequent in patients with preoperative CRP higher than $7 \mathrm{mg} / \mathrm{I}(28.1 \%$ vs. $11.6 \%, \mathrm{P}=0.036)$, whereas in our study post-operative infection were more frequent in patients with preoperative jaundices with PCT higher than $1 \mathrm{ng} / \mathrm{dl}$ (P value was 0.017 ).

CRP on POD 4 yielded and accuracy of $80.4 \%$ and $90 \%$ (In our study) for the detection of postoperative septic complications. In the multivariate analysis, CRP higher than $125 \mathrm{mg} / \mathrm{l}$ at POD 4 was the only predictive factor which remained significant for septic complications. A cut off $125 \mathrm{mg} / 1$ in the CRP value at POD 4 yielded a sensitivity of $81.8 \%$, a specificity of $64.44 \%$ and which were comparable to our study, when CRP was equal or higher than $110 \mathrm{mg} / \mathrm{dl}$ at POD 4 yielded a sensitivity of $90 \%$ and specificity of $92 \%$.

Our results suggest that PCT measurements may be useful for early diagnosis of septic postoperative complications. PCT level $>1.5 \mathrm{ng} / \mathrm{dl}$ associated with infection on day 4 could allow diagnosis of postoperative septic complications with a high probability (specificity $\sim 100 \%$ ). This is in agreement with Reith et $\mathrm{al}^{\left[{ }^{[15]}\right.}$ who studied the prognostic capacity of elevated PCT levels in 70 patients undergoing elective colorectal surgery and aortic surgery.
Though many studies reveals as post-operative day advances, the predictability of inflammatory markers became low, but in our study on day 7 of post-operative period the sensitivity and specificity of markers like S.CRP and S.PCT was high when keeping a cut off value and even specificity of S.PCT reaching almost $100 \%$. This shows the high predictability of infection by S.PCT as an inflammatory marker. According to these results measuring S.CRP or S.PCT on the POD 4 or 7 may contribute to a safe discharge from hospital after hepatobiliary surgery. Patients with values above cut off should undergo further evaluation to search for any postoperative complications.

This study shows those who were clinically septic post operatively have elevated levels of serum CRP and Procalcitonin (PCT), whereas serum PCT is more specific and sensitive than serum CRP. Early identification of patients with insidious septic illness allows early therapeutic intervention which may favorably influence outcome. Future studies in larger groups of patients should specifically address this issue.

\section{Conclusion}

A cross sectional study on the value of C-reactive protein and Procalcitonin as an indicator predicting post-operative infection following hepato biliary surgery was conducted in 42 patients during the span of 2 years. It was found that 30 patients have developed post-operative infective complication. The values of serum CRP and PCT on these 30 patients on 4th and 7th POD were significantly high. The sensitivity and specificity value of both the inflammatory markers were also found to be statistically significant in predicting post-operative infective complication following hepatobiliary surgery. It is further found that serum PCT value is more sensitive and specific than that of CRP while predicting such infection.

However, further study in larger series and longer follow up is required so as to enable us to come to a final conclusive data on this topic.

\section{References}

1. Velasco E, Santosthuler L, Martins C, Decastrodias L, Dasecconalves V. Risk factors for infectious complications after abdominal surgery for malignant disease. Am J Inf Control. 1996;24(1):1-6. Available from: https://dx.doi.org/10.1016/ s0196-6553(96)90046-2. doi:10.1016/s0196-6553(96)900462.

2. Pittet D, Rangel-Frausto S, Li N, Tarara D, Costigan M, Rempe L, et al. Systemic inflammatory response syndrome, sepsis, severe sepsis and septic shock: Incidence, morbidities and outcomes in surgical ICU patients. Intensive Care Med. 1995;21(4):302-309. Available from: https://dx.doi.org/10. 1007/bf01705408. doi:10.1007/bf01705408. 
3. Rangel FS, Pittet D, Costigan M, Wang T, Davis CS, P R. The natural history of the systemic inflammatory response syndrome (SIRS): A prospective study. JAMA. 1985;273:117140.

4. Rivers E, Nguyen B, Havstad S, Ressler J, Muzzin A, Knoblich B, et al. Early Goal-Directed Therapy in the Treatment of Severe Sepsis and Septic Shock. New England J Med. 2001;345(19):1368-1377. Available from: https://dx.doi.org/ 10.1056/nejmoa010307. doi:10.1056/nejmoa010307.

5. Mokart D, Capo C, Blache JL, Delpero JR, Houvenaeghel G, Martin C, et al. Early postoperative compensatory antiinflammatory response syndrome is associated with septic complications after major surgical trauma in patients with cancer. $\quad$ Br J Surg. 2002;89(11):1450-1456. Available from: https://dx.doi.org/10.1046/j.1365-2168.2002.02218.x. doi:10.1046/j.1365-2168.2002.02218.x.

6. Noori NM, Shahramian I, Teimouri A, Keyvani B, Mahjoubifard M. Serum Levels of Tumor Necrosis Factor- $\alpha$ and Interleukins in Children with Congenital Heart Disease. J Tehran Heart Cent. 2017;12(1):15-22.

7. Deitmar S, Anthoni C, Palmes D. Are leukocytes and CRP early indicators for anastomotic leakage after esophageal resection. Zentralbal Chir. 2009;134:83-92.

8. Assicot M, Bohuon C, Gendrel D, Raymond J, Carsin H, Guilbaud J. High serum procalcitonin concentrations in patients with sepsis and infection. Lancet. 1993;341(8844):515-518. Available from: https://dx.doi.org/10.1016/0140-6736(93) 90277-n. doi:10.1016/0140-6736(93)90277-n.

9. Hack CE, Zeerleder S. The endothelium in sepsis: Source of and a target for inflammation. Critical Care Med. 2001;29:S21S27. Available from: https://dx.doi.org/10.1097/00003246200107001-00011. doi:10.1097/00003246-200107001-00011.

10. Bota DP, Nuffelen MV, Zakariah AN, Vincent JL. Serum levels of C-reactive protein and procalcitonin in critically ill patients with cirrhosis of the liver. J Lab Clin Med. 2005;146(6):347351. Available from: https://dx.doi.org/10.1016/j.lab.2005.08. 005. doi:10.1016/j.lab.2005.08.005.

11. Matthiessen P, Henriksson M, Hallböök O, Grunditz E, Norén B, Arbman G. Increase of serum C-reactive protein is an early indicator of subsequent symptomatic anastomotic leakage after anterior resection. Colorectal Dis. 2007;0(0):070730035900001-??? Available from: https://dx.doi.org/10.1111/j.1463-1318.2007.01300.x. doi:10.1111/j.1463-1318.2007.01300.x.

12. Simon L, Gauvin F, Amre DK, Saint-Louis P, Lacroix J. Serum Procalcitonin and C-Reactive Protein Levels as Markers of Bacterial Infection: A Systematic Review and Meta-analysis. Clin Inf Dis. 2004;39(2):206-217. Available from: https://dx. doi.org/10.1086/421997. doi:10.1086/421997.

13. Oberhofer D, Juras J, Pavičić AM, Žurić IR, Rumenjak V. Comparison of C-reactive protein and procalcitonin as predictors of postoperative infectious complications after elective colorectal surgery. Croatian Med J. 2012;53(6):612619. Available from: https://dx.doi.org/10.3325/cmj.2012.53. 612. doi:10.3325/cmj.2012.53.612.

14. Mallet E, Lanse X, Devaux AM, Ensel P, Basuyau JP, Brunelle P. Hypercalcitoninaemia in fulminant meningococcaemia in children. Lancet. 1983;321(8319):294-294. Available from: https://dx.doi.org/10.1016/s0140-6736(83)91704-x. doi:10.1016/s0140-6736(83)91704-x.

15. Reith HB, Mittelkötter U, Debus ES, Küssner C, Thiede A. Procalcitonin in Early Detection of Postoperative Complications. Digestive Surg. 1998;15(3):260-265. Available from: https: //dx.doi.org/10.1159/000018625. doi:10.1159/000018625.

Copyright: (C) the author(s), 2020. It is an open-access article distributed under the terms of the Creative Commons Attribution License (CC BY 4.0), which permits authors to retain ownership of the copyright for their content, and allow anyone to download, reuse, reprint, modify, distribute and/or copy the content as long as the original authors and source are cited.

How to cite this article: Joshua CC, Sreejith V, Sreekumar A. Serum C - reactive protein and Pro-Calcitonin as an Indicator in Post-Operative Infection after Hepatobiliary Surgery. Acad. J Surg. 2020;3(1):64-70.

DOI: dx.doi.org/10.47008/ajs/2020.3.1.14

Source of Support: Nil, Conflict of Interest: None declared. 